\title{
Radiographic signs of pulmonary embolism and pulmonary infarction
}

\author{
S. TALBOT, B. S. WORTHINGTON, and E. J. ROEBUCK \\ General Hospital, Nottingham
}

A comparative analysis of the radiographic features in a group of patients dying with pulmonary embolism and/or pulmonary infarction, and a group without but suspected of having the conditions before death, showed that two radiologists could diagnose pulmonary infarction correctly in $70 \%$ of cases. The most useful radiographic sign was elevation of the diaphragm often with slight atelectasis and a small unilateral effusion. The plain chest radiograph was of little value in diagnosing pulmonary embolism without infarction.

Many radiographic signs of pulmonary embolism and infarction have been described in clinical cases (Fleischner, 1959; Westermark, 1938). However, pulmonary embolism and infarction are frequently wrongly diagnosed, often being missed and sometimes diagnosed when pulmonary infection or carcinoma are present. Marshall (1965) stressed three radiological signs of infarction, namely, the shadow produced by the lesion, evidence of a pleural effusion, and a raised diaphragm. Less frequent features associated with embolism are increased radiotranslucency, pulmonary oedema, and prominent main pulmonary arteries. These may, however, occur in other conditions, and it was therefore decided to take a control group of patients to find if any of these changes are usually diagnostic of infarction, and also to show whether radiologists can diagnose pulmonary embolism and infarction from routine plain radiographs. To be certain of the diagnosis, only patients in whom necropsy evidence was available were studied.

\section{PATIENTS AND METHODS}

From the hospital necropsy records of 1967 to 1970 inclusive, cases of pulmonary embolism and infarction were selected if they had a chest radiograph. From the case records the date of the radiograph in relation to death was determined, and radiographs showing evidence of infarction $(>3 \mathrm{~cm}$ in diameter) or embolism which was later proved at necropsy were selected. This usually meant that only cases in whom infarction had been present for 48 hours or cases with necropsy evidence of fresh infarction, who had had a radiograph performed from 12 to 24 hours before death, were included. Of the 66 cases with emboli/infarction (Table I), 57 had radiographs within one week of death (mean 1.96 days, SD 1.2), and six, of whom three had fibrosed infarcts, within three weeks. Three cases of sudden massive embolism had radiographs taken shortly after symptoms occurred and within four hours of death.

T A B LE I

PATHOLOGY OF NECROPSY CASES

\begin{tabular}{|c|c|c|}
\hline & Pathological Diagnosis & No. of Necropsies \\
\hline $\begin{array}{l}\text { Control } \\
\text { Thromboembolism }\end{array}$ & $\begin{array}{l}\text { No emboli or infarcts } \\
\text { Pulmonary emboli only } \\
\text { Pulmonary infarction } \\
\text { only } \\
\text { Pulmonary embolism } \\
\text { and infarction }\end{array}$ & $\begin{array}{r}57 \\
17 \\
3 \\
46\end{array}$ \\
\hline
\end{tabular}

Twenty-three per cent of these cases had fractured femurs, and $6.9 \%$ died following abdominal surgery. Although it was difficult to identify the time of onset of embolism or infarction this was usually a few days from death (4.8 days, SD 2.9 days). Clinical features which in retrospect were typical of pulmonary emboli/ infarction were recorded for 39 patients. These were haemoptysis (10 patients), sudden dyspnoea (21 patients), pleuritic pain ( 9 patients), angina (3 patients), and syncope ( 5 patients). Often there was gradual deterioration with confusion and coma. Signs of consolidation were noted in 15 patients and signs of a 'pleural effusion' in five patients. Often the radiographs were performed to elucidate coincidental infections or cardiac failure.

The pathological examination included examination of the major, lobar, and segmental vessels. If thrombus was firmly adherent it was assumed that embolism had occurred at least 48 hours before death, and if lightly adherent at least 24 hours before death. Additional fresh embolism was not considered. There was one case with an organized fibrosed pulmonary arterial occlusion, which was probably embolic. 
At necropsy only 16 cases had unilateral emboli: of the 63 cases with emboli, 21 had major pulmonary artery emboli ( \pm other emboli), 20 had lobar emboli ( \pm segmental emboli), and 22 had segmental emboli only. Of the 49 cases with infarcts, massive lobar infarcts were found in 7 , infarction $(>3 \mathrm{~cm})$ in 35 , and multiple small infarcts $(<3 \mathrm{~cm})$ were found in 7 .

At the time of the radiograph, in 31 cases there was right lower lobe infarction and in 23 cases left lower lobe infarction: eight were bilateral. There were two cases with right upper lobe infarction alone, and of three left upper lobe infarctions two also had infarction elsewhere. There was one case with an abscess secondary to a right lower lobe infarction.

A control series consisted of 57 radiographs from 1969 to 1970 on patients in whom the diagnosis of pulmonary embolism or infarction was suspected at the time of their radiographs, but who did not have these conditions at necropsy; $24.5 \%$ were surgical cases. The causes of death in this control group were usually pneumonia (29 cases), left ventricular failure (10 cases), myocardial infarction (7 cases), and carcinoma (6 cases).

The combined series of radiographs were then shown to two radiologists, $A$ and $B$, without the patient's name or the pathological features being known and they were asked to comment on the radiological features and whether they thought pulmonary infarction was present. They also commented on the visibility of the pulmonary vessels and whether they were normal or compatible with embolism. (If the lobar vessels were obscured by consolidation, they were considered abnormal.) They commented on any other features suggestive of embolism, and particularly cardiomegaly, pleural effusions, pulmonary oedema, and pulmonary venous engorgement. Elevation of the diaphragm was noted if the right side was more than 1 inch higher than the left, or if the left side was higher than the right.

All available radiographs were examined, but portable supine radiographs were included only when they were part of a series of examinations. Table II shows the type of radiographs performed for both controls and patients with pulmonary emboli/ infarction.

T A B L E I I

NUMBER AND FORM OF RADIOGRAPHIC EXAMINATIONS

\begin{tabular}{l|cc}
\hline \multirow{2}{*}{ Radiographic Examination } & \multicolumn{2}{|c}{ No. of Necropsies } \\
\cline { 2 - 3 } & Control & Pulmonary Emboli/Infarcts \\
\hline Multiple examinations & 12 & 21 \\
PA and lateral & 9 & 9 \\
PA only & 26 & 23 \\
AP only & 10 & 13 \\
\hline
\end{tabular}

\section{RESULTS}

An analysis of the correct and incorrect diagnoses is shown in Table III. Below this are details of the patients on whom the radiologists made the correct diagnosis, either by diagnosing infarction or embolization when they were present or by not doing so when they were absent. Below this the incorrect diagnoses are analysed by a similar method.

T A B L E I I I

RADIOLOGICAL DIAGNOSIS ${ }^{1}$ CORRELATED WITH PATHOLOGICAL DIAGNOSIS

\begin{tabular}{|c|c|c|c|c|}
\hline & \multicolumn{2}{|c|}{ Radiologist A } & \multicolumn{2}{|c|}{ Radiologist B } \\
\hline & Emboli & Infarcts & Emboli & Infarcts \\
\hline $\begin{array}{l}\text { Correct diagnosis } \\
\text { Incorrect diagnosis }\end{array}$ & $\begin{array}{l}66 \\
57\end{array}$ & $\begin{array}{l}92 \\
31\end{array}$ & $\begin{array}{l}71 \\
52\end{array}$ & $\begin{array}{l}81 \\
42\end{array}$ \\
\hline $\begin{array}{l}\text { Correct positive } \\
\text { Correct negative } \\
\text { Incorrect positive } \\
\text { Incorrect negative }\end{array}$ & $\begin{array}{l}19 \\
47 \\
13 \\
44\end{array}$ & $\begin{array}{r}24 \\
68 \\
6 \\
25\end{array}$ & $\begin{array}{l}27 \\
44 \\
16 \\
36\end{array}$ & $\begin{array}{l}17 \\
64 \\
10 \\
32\end{array}$ \\
\hline
\end{tabular}

${ }^{1} \mathrm{~A}$ positive radiological diagnosis was made if there were radiological features of infarction or emboli.

The percentage correct diagnosis of pulmonary infarction was $74.7 \%$ for $A$ and $65.8 \%$ for $B$. The percentage correct diagnosis of pulmonary embolism was $53.6 \%$ for A and $57.7 \%$ for B. Thus the diagnosis was correct in $70 \%$ of patients with pulmonary infarction and in $55 \%$ of patients with pulmonary embolism.

The probability of these figures being due to chance for radiologist $A$ was $<0.01$ for infarction but not significant for embolization, $\chi^{2}$ being 24.6 and 0.75 respectively. For radiologist $B, \chi^{2}=6.54$ $(\mathrm{P}<0.01)$ for infarction and $\chi^{2}=2.86(\mathrm{P}<0.10)$ for embolism.

T A B L E I V

RADIOGRAPHIC FEATURES RELATED TO PATHOLOGY IN CASES OF PULMONARY EMBOLISM/INFARCTION AND CONTROL CASES

\begin{tabular}{l|c|c}
\hline & $\begin{array}{c}\text { Pulmonary Emboli/Infarcts } \\
\text { (66 cases) }\end{array}$ & $\begin{array}{c}\text { Controls } \\
\text { (57 cases) }\end{array}$ \\
\hline $\begin{array}{l}\text { Cardiomegaly } \\
\text { No cardiomegaly }\end{array}$ & 41 & 21 \\
Elevated diaphragm & 24 & 36 \\
Bilateral pleural & 26 & 5 \\
effusions & 5 & 5 \\
$\begin{array}{l}\text { Unilateral large } \\
\text { effusion }\end{array}$ & 4 & 8 \\
Unilateral small & 12 & 7 \\
effusion & 11 & 10 \\
$\begin{array}{l}\text { Pulmonary venous } \\
\text { hypertension }\end{array}$ & 8 & 7 \\
Bilateral shadowing & 3 & 0 \\
\hline Linear atelectasis & & \\
\hline
\end{tabular}

The figures refer to the numbers of patients in each group with this radiological feature.

Table IV shows some radiological features that are usually associated with infarction and embolism. The only two that had significant association were elevation of the diaphragm (Fig. 1) and cardiomegaly (one radiograph was not assessed for 


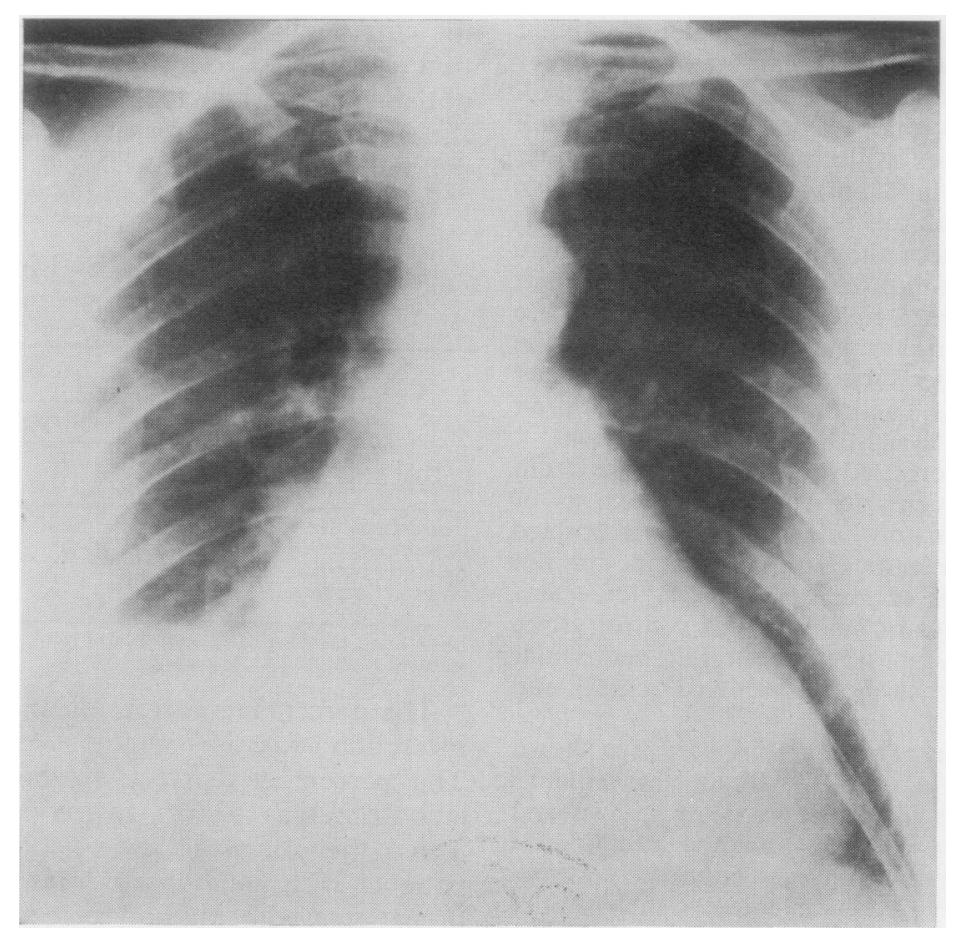

FIG. 1. Radiograph of a patient who subsequently died with pulmonary embolism/infarction: note high right diaphragm and cardiomegaly.

cardiomegaly). Correlation of an elevated diaphragm and pulmonary infarction was most significant $\left(\chi^{2}=33.3, \mathbf{P}<0.01\right)$. This, therefore, seems to be a significant sign of pulmonary infarction, although it did occur in one case of subphrenic abscess, in one case of basal atelectasis, and in three cases of pneumonia. Obese patients or patients having supine radiographs usually had bilateral elevation of the diaphragm, which was difficult to assess.

Basal collapse could often be seen on the radiograph with crowding of vascular markings; linear atelectasis was noted in three cases but in none of the controls (Fig. 2).

There was no difference in the diagnostic accuracy of right-sided (41) or left-sided (38) emboli and infarcts, but only one out of five upper lobe infarctions was detected, presumably due to the greater distance of such infarcts from the diaphragm.

The diagnostic accuracy was not improved if pulmonary infarction and embolism were com- bined in the pathological and radiographic analysis, as in Table $V$ (for radiologist $A, \chi^{2}=$ 6.93, $\mathrm{P}<0.01$, and for radiologist $\mathrm{B}, \chi^{2}=3.24, \mathrm{P}<$ $0 \cdot 10)$. Agreement between radiologists is expressed in Table VI $\left(\chi^{2}=42.7, P<0.01\right.$ for infarction; $\chi^{2}=10.4, P<0.01$ for emboli). The time of the radiograph in relation to the age of the infarction made no difference to diagnostic accuracy.

T A B L E V

RADIOGRAPHIC DIAGNOSIS OF PULMONARY EMBOLISM AND/OR INFARCTION CORRELATED WITH PATHOLOGICAL DIAGNOSIS

\begin{tabular}{l|cc}
\hline \multicolumn{1}{c|}{ Pathology } & $\begin{array}{c}\text { No Emboli } \\
\text { or Infarction }\end{array}$ & $\begin{array}{c}\text { Abnormality of } \\
\text { Infarction/Emboli }\end{array}$ \\
\hline $\begin{array}{l}\text { Radiologist } A \\
\text { Pulmonary } \\
\text { emboli/infarction }\end{array}$ & 32 & 34 \\
Control pathology & 44 & 13 \\
\hline $\begin{array}{l}\text { Radiologist } B \\
\text { Pulmonary } \\
\text { emboli/infarction }\end{array}$ & 36 & 30 \\
Control pathology & 41 & 16 \\
\hline
\end{tabular}




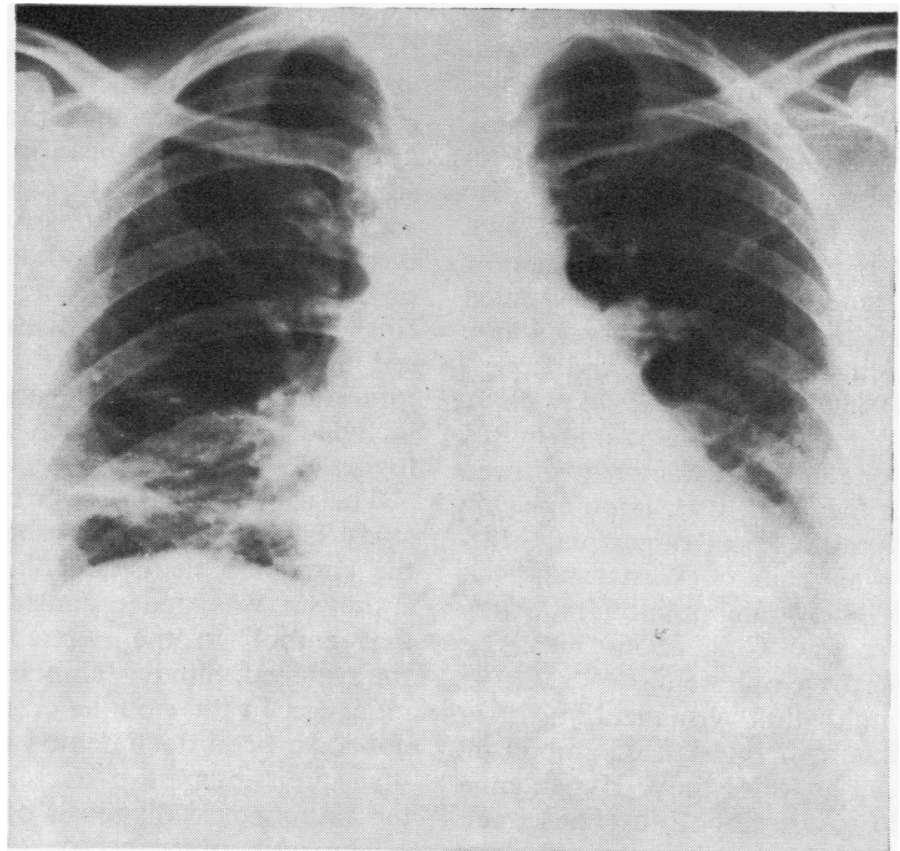

FIG. 2. Radiograph of a patient who subsequently died with pulmonary embolism/infarction: note basal lung collapse with a linear atelectasis at the right base.

TABLE VI

AGREEMENT AND DISAGREEMENT BETWEEN RADIOLOGISTS AND THEIR CORRELATION WITH PATHOLOGICAL DIAGNOSIS

\begin{tabular}{l|ccc}
\hline \multirow{2}{*}{} & \multicolumn{3}{|c}{ Agreement among Radiologists } \\
\cline { 2 - 4 } & Correct & Incorrect & No. of Cases \\
\hline Emboli & 48 & 34 & 82 \\
\hline Infarction & 76 & 26 & 102 \\
\hline & Disagreement among Radiologists \\
\cline { 2 - 4 } & Correct & Correct & No. of Cases \\
\hline Emboli & (A) & (B) & \\
\hline Infarction & 18 & 23 & 41 \\
\hline
\end{tabular}

\section{DISCUSSION}

From this retrospective controlled necropsy study, two radiologists were able to diagnose pulmonary infarction correctly in $70 \%$ of cases.

Smith (1938), Short (1951), Macleod and Grant (1954), Smith (1953), and Stein et al. (1959) have all described radiological abnormalities in pulmonary infarction but all these series have been predominantly of clinical cases without necropsy confirmation. Although these abnormalities may occur in infarction they do not all appear to be of great diagnostic value.

Short (1951) found pleural involvement in $56 \%$ of patients with pulmonary infarction, but pleural effusion was found in only $33 \%$. In the present study $26.1 \%$ of patients with pulmonary infarcts had small unilateral effusions, and $12.3 \%$ of patients with pneumonic consolidation. Chang (1967) and Chang and Davis (1965) suggested that dilatation of one or other pulmonary artery was an important sign of pulmonary infarction but their observations were uncontrolled and few necropsies were reported. Dilatation, which later regresses, in conjunction with other changes is useful supportive evidence of pulmonary infarction. However, an isolated observation (which is usually all there is) of a left pulmonary artery of $17 \mathrm{~mm}$ or more in width, or a right pulmonary artery of more than $16 \mathrm{~mm}$, with measurements made at the widest point of the arteries (usually between the eighth and ninth ribs posteriorly in deep inspiration) does not seem of any value in the diagnosis of infarction or embolism. In this series, measurements were made when the vessels were visible on such radiographs and no difference 
was observed between the controls and patients with pulmonary emboli or infarction. Obliteration of pulmonary vessels and areas of radiotranslucency were also inadequate signs of emboli.

Radiological evidence of embolism without infarction was stressed by Westermark (1938). He found absence of pulmonary vascular shadows, sometimes with enlargement of the hilar shadow after large emboli, and others have also noted this (Teplick, Haskin, and Steinberg, 1964 ; Arendt and Rosenberg, 1959 ; Shapiro and Rigler, 1948 ; Torrance, 1963 ; Woesner et al., 1953). Stein et al. (1959) did not observe it and in the present study only one case satisfactorily showed it. In animal experiments it was impossible to produce an area of radiological oligaemia (Marshall et al., 1963). This sign of Westermark has also been reported in chronic pulmonary artery thrombosis (Hollister and Cull, 1956) but it is often found in areas of emphysema.

Laur (1963) thought that visualization of a defect in a vessel was a direct sign of embolism, but this was not seen in this study. Hyperaemia on the opposite side to an embolism (Fleischner, 1959) and pulmonary oedema due to an embolism (Fleischner, 1959) were not observed in this study. Left ventricular failure was often found in both groups in the present study but there was no evidence of an association between this and embolism and infarction. Fleischner (1962) considered areas of radiotranslucency or abrupt termination of blood vessels as important radiographic signs of emboli but these signs seem rare and not easy to distinguish from areas of emphysema. Areas of pulmonary shadowing or cardiomegaly may obscure the pulmonary vessels and only serial films will elucidate such changes.

The failure of the radiologists to diagnose pulmonary embolism was not due to the method of analysis. They rarely noted radiological features of emboli. Therefore any other method of analysis would have resulted in a larger number of false negative diagnoses and would not have improved the diagnostic accuracy. The standard of the radiographs in the control and embolic groups was similar, in view of the comparability of their clinical condition, and an error in diagnosis of pulmonary embolism/infarction was as often false positive as false negative in both control and embolic groups.

There were equal proportions of surgical cases in both control and embolic groups although there were few traumatic cases in the control group. Therefore elevation of the diaphragm after laparotomy could not explain the high inci- dence of this finding in the embolic group, and $\stackrel{\overrightarrow{5}}{\frac{\bar{S}}{+}}$ the inequality of such elevation on the two sides? was often of diagnostic value even in supine radio- $\frac{\bar{\sigma}}{\bar{N}}$ graphs. However, the radiologists' diagnostic $\frac{\text { क }}{\sigma}$ accuracy could have been increased by the exclu- $\propto$ sion of infarcts that were too recent for the $\%$ analysis. There is doubt as to the interval between $\vec{\circ}$ the onset of embolism and symptoms and signs:of infarction (and sometimes of embolism) occur- $\vec{\omega}$ ring, and although such features had often occurred they could not be used to date the time of $\overrightarrow{\vec{x}}$ infarction. Thus smaller and earlier infarcts, if included, might have been missed by the radio- $i$ logists.

The usual criticism of a retrospective necropsy $ळ$ study is that emboli may be missed. Since in all 은 the control patients the diagnosis of pulmonary embolism was under consideration it is unlikely that emboli in the segmental vessels or above $\stackrel{\oplus}{\circ}$ were missed. Smaller emboli are of unknown sig. $\stackrel{?}{\longrightarrow}$ nificance. In the embolic group all the emboli may $\vec{\varphi}$ not have been documented but it is unlikely that $\omega$ such omissions have decreased the accuracy of $\square$ the radiologists' diagnosis of embolism.

The only other necropsy study of pulmonary embolism and infarction was that of Hampton and Castleman (1940) in which necropsy findings $\frac{}{\perp}$ were correlated with chest radiographs performed $\stackrel{2}{\vec{A}}$ post mortem in the erect position. This may be $\frac{3}{3}$ why they did not detect elevation of the dia- phragm. An infarct could be of any shape in the PA projection but often appeared like a cushion. They stressed that in the PA or AP radiographs the shadow may be masked by the heart or diaphragm, and that it was missed in 0 $25 \%$ of cases. It was easily confused with areas of 3 . pulmonary oedema, infection, and atelectasis.

Linear atelectasis are signs of old infarction 3 (Fleischner, 1962). Simon (1970) felt that such 0 lines could be due to secondary pulmonary venous thrombosis and then the line was directed to the hilum. In retrospect only one case could be considered to have this sign and only one $\sigma$ other had a small linear shadow which was due N to an old infarct. Good lateral radiographs would N probably have helped in detecting such lesions but are usually unobtainable.

Although by no means diagnostic (Laur, $1963 ;$;유 Barritt and Jordan, 1961), the most useful sign $\stackrel{\infty}{?}$ of pulmonary infarction in PA radiographs in the present study was an elevated diaphragm. 0 However, this sign was present in less than $50 \% \stackrel{\mathbb{D}}{\circ}$ of cases and its absence should not make the $\underset{\mathbb{D}}{\mathbb{P}}$ clinician exclude pulmonary embolism and $\varrho$ infarction. 
We are grateful to the Departments of Radiography and Photography for their assistance, and also to the Department of Pathology for necropsy details.

\section{REFERENCES}

Arendt, J., and Rosenberg, M. (1959). Thromboembolism of the lungs. Amer. J. Roentgenol., 81, 245.

Barritt, D. W., and Jordan, S. C. (1961). Clinical features of pulmonary embolism. Lancet, 1, 729.

Chang, C. H. (1967). Radiological considerations in pulmonary embolism. Clin. Radiol., 18, 301.

- and Davis, W. C. (1965). A roentgen sign of pulmonary infarction. Clin. Radiol., 16, 141.

Fleischner, F. G. (1959). Unilateral pulmonary embolism with increased compensatory circulation through the unoccluded lung. Radiology, 73, 591.

—, (1962). Pulmonary embolism. Clin. Radiol., 13, 169.

Hampton, A. O., and Castleman, B. (1940). Correlation of post-mortem chest teleroentgenograms with autopsy findings, with special reference to pulmonary embolism and infarction. Amer. J. Roentgenol., 43, 305.

Hollister, L. E., and Cull, V. L. (1956). The syndrome of chronic thrombosis of the major pulmonary arteries. Amer. J. Med., 21, 312.

Laur, A. (1963). Roentgen diagnosis of pulmonary embolism and its differentiation from myocardial infarction. Amer. J. Roentgenol., 90, 632.

Macleod, J. G., and Grant, I. W. B. (1954). A clinical, radiographic and pathological study of pulmonary embolism. Thorax, 9, 71.
Marshall, R. J. (1965). Pulmonary Embolism. Mechanism and Management. Thomas, Springfield, Illinois.

Marshall, R., Sabiston, D. C., Allison, P. R., Bosman, A. R., and Dunnill, M. S. (1963). Immediate and late effects of pulmonary embolism by large thrombi in dogs. Thorax, 18, 1.

Shapiro, R., and Rigler, L. G. (1948). Pulmonary embolism without infarction. Amer. J. Roentgenol., 60, 460.

Short, D. S. (1951). A radiological study of pulmonary infarction. Quart. J. Med., 20, 233.

Simon, G. (1970). Further observations on the long line shadow across a lower zone of the lung. Brit. J. Radiol., 43, 327.

Smith, K. S. (1938). The radiology of pulmonary infarction. Quart. J. Med., 7, 85.

Smith, M. J. (1953). Roentgenographic aspects of complete and incomplete pulmonary infarction. Dis. Chest, 23, 532.

Stein, G. N., Chen, J. T., Goldstein, F., Israel, H. L., and Finkelstein, A. (1959). The importance of chest roentgenography in the diagnosis of pulmonary embolism. Amer. J. Roentgenol., 81, 255.

Teplick, J. G., Haskin, M. E., and Steinberg, S. B. (1964). Changes in the main pulmonary artery segment following pulmonary embolism. Amer. J. Roentgenol., 92, 557.

Torrance, D. J. (1963). The Chest Film in Massive Pulmonary Embolism. Thomas, Springfield, Illinois.

Westermark, N. (1938). On the roentgen diagnosis of lung embolism. Acta radiol. (Stockh.), 19, 357.

Woesner, M. E., Gardiner, G. A., and Stilson, W. L. (1953). Pulmonary embolism does not necessarily mean pulmonary infarction. Amer. J. Roentgenol., 69, 380. 